\title{
FORMAÇÃO CONTINUADA DE PROFESSORES DE QUÍMICA: UM PROGRAMA VOLTADO PARA A CONSTRUÇÃO DO CO- NHECIMENTO ESCOLAR
}

Natalina Aparecida Laguna Sicca*

\section{RESUMO}

Este trabalho é uma análise do programa de formação continuada de professores de química das $1^{a}$ e $2^{a}$ Delegacias de Ensino de Ribeirão Preto(SP), vigente durante o ano de 1996, voltado para a implementação da Proposta Curricular para o Ensino de Química-2ºrau do Estado de São Paulo. Teve como objetivo a criação de um espaço coletivo para a construção do currículo, a partir de estudos temáticos tendo em vista o ensino. O programa, apresentou, ainda, a busca de novos tipos de gestão para programas de formação de professores.

\section{INTRODUÇÃO}

Pretende-se discutir neste trabalho a organização de um programa voltado para a formação de professores de química, pautado na premissa de que o professor articula saberes na construção do conhecimento escolar, promovendo assim recontextualizações da ciência química tendo em vista a aprendizagem do aluno. O programa objetivou a criação de espaços coletivos de reflexão de professores e especialistas visando interferir no processo de produção do conhecimento escolar (termo utilizado por Santos, 1994).

O plano para esta apresentação consta de três momentos. O primeiro localiza as razões históricas para a construção do programa de formação continuada de professores de química, a partir de uma incursão nas práticas oficiais voltadas para a capacitação de professores de química do Estado de São Paulo, desde a década de 70 . O segundo, apresenta as concepções que fundamentaram o programa e uma análise do mesmo, detalhando um dos seis temas estudados pelos professores. O terceiro apresenta as considerações finais em face do processo desenvolvido.

No Estado de São Paulo os primeiros programas oficiais voltados para a capacitação' de professores de Química foram iniciados na década de 70 e pressupunham que a melhoria do ensino da área de ciências necessariamente

* Faculdade de Filosofia Ciências e Letras de Ribeirão Preto. Departamento de Psicologia e Educação Universidade de São Paulo. Brasil.

1- Capacitação foi o termo utilizado pela Secretaria de Estado da Educação do Estado de São Paulo para designar os programas voltados para o treinamento de professores. 
deveria se dar por meio do uso da técnica da redescoberta. Para este fim foram promovidos treinamentos de professores, que objetivavam a divulgação de "pacotes instrucionais", os Subsídios para a Implementação da Proposta Curricular $^{2}$, alicerçados na referida Proposta ${ }^{3}$ que anteriormente tinha sido elaborada por uma equipe de professores universitários.

O programa ${ }^{4}$ concebia o professor como um técnico que se legitima enquanto um profissional especializado ao possuir a técnica precisa e segura para atingir o que pretende. $\mathrm{O}$ fazer pedagógico, na perspectiva tecnicista, tornava-se sobretudo instrumental, dirigido para a solução de problemas, de modo a serem aplicadas teorias e técnicas científicas. (Pèrez Gomez, 1992)

A concepção do ensino fora decidida, pelos especialistas designados pela Secretaria de Educação (SE) e a execução atribuída aos professores, nas escolas. O Programa de Capacitação pautado na racionalidade técnica, valorizava os recursos didáticos em detrimento da atividade docente, reforçando assim, a tutela do professor, que deveria decidir $o$ que ensinar baseando-se nas sugestões da Proposta Curricular e como ensinar utilizando o material instrucional publicado pela SE, aplicando em suas aulas as atividades práticas dos Subsídios. Tal organização favorecia a divisão do trabalho separando até espacialmente os que pensam e os que executam.

O referido programa de capacitação não foi acompanhado de alterações significativas na organização do trabalho na escola e no ambiente escolar, no sentido de favorecer a criação de um espaço de trabalho/aprendizagem para o professor. $\mathrm{O}$ que acompanhou o programa de capacitação, que atingiu menos que $10 \%$ dos professores de química da rede estadual na época, foi a distribuição de material de laboratório e a publicação de uma resolução ${ }^{5}$ que permitia o desdobramento das classes em duas turmas para as aulas práticas, desde que os professores assim optassem.

Na década de 80, durante outro governo estadual (1982-1986), os programas de capacitação de professores de química, tomaram outra direção. Dentro do processo de reorganização curricular foi construída uma Proposta

2- Os Subsídios eram uma coletânea de atividades práticas de laboratório, planejadas para serem executadas nos laboratórios das escolas com material simples, posteriormente distribuído para as escolas dos professores treinados. As atividades continham os objetivos a serem atingidos, um roteiro a ser seguido e os resultados a serem esperados.

3- São Paulo(Estado). Secretaria da Educação. Coordenadoria de Estudos e Normas Pedagógicas. Proposta Curricular de Química para o segundo grau. SE/CENP. 1978

4- Os Treinamentos eram parte do projeto "Implementaçāo da Proposta Curricular . Cursos de formação de professores monitores e de Treinamentos centrais de Biologia, Física e Química. CENP/DRHU. 1980-1981.

5- Resoluçāo $S E, n^{\circ} 95$, de 20 de setembro de 1978, publicada no DO de 04 de outubro de 1978 
Curricular para o ensino de Química com a participação dos professores da escola secundária e da Universidade, sob a coordenação dos técnicos da SE. Os que participaram do processo estabelecido vivenciaram momentos de reflexão e redefinição de suas próprias metodologias de ensino.

Para os organizadores desse programa, o professor, foi concebido como um profissional, um intelectual transformador, que deveria decidir o que, como e para que ensinar e analisar o contexto onde se dá o ensino. Foi, para este fim, prevista a criação de um processo coletivo de produção e divulgação de conhecimento.

Se o programa anterior de formação de professores promoveu um controle técnico sobre o trabalho do professor, esse buscava consolidar a autonomia da profissão docente.

Entretanto o projeto, que atingiu principalmente os professores-representantes das diferentes regiões do Estado, foi interrompido com a mudança de governo, não tendo sido acompanhado da necessária reorganização do trabalho do professor, no sentido de promover na escola um ambiente de trabalho e aprendizagem e, nem mesmo, houve continuidade dos processos previstos para a implementação da Proposta Curricular.

No governo estadual seguinte, o rol de conteúdos da referida Proposta passou a ser obrigatório, tendo sido desvirtuado o projeto inicial sob o qual fora concebida. Os programas voltados para a capacitação de professores, resumindo-se a encontros esporádicos, tiveram caráter pontual na vida dos mesmos.

Relacionando os programas voltados para a formação de professores, até o início dos anos 90, percebe-se continuidades e rupturas. O discurso oficial, as estratégias, a racionalidade implícita nos programas de formação de professores sofreram rupturas, decorrentes da descontinuidade da política administrativa da gestão da educação. Porém verificamos continuidades: as condições de trabalho do professor não foram alteradas, assim como o ambiente escolar, no sentido de favorecerem a implementação dos programas oficiais. (Sicca, 1996)

Deve-se registrar ainda, durante todo o período, o despontar de táticas pelos professores e técnicos da própria SE, voltadas para o estabelecimento de processos reflexivos caracterizados pela troca de conhecimento escolar, deixando evidente porém, a frágil organização de classe.(Sicca, 1996)

Se nesta história, os professores mostraram a necessidade de refletir sobre a prática educativa, o que já vinha acontecendo nos programas oficiais mais recentes, encontra-se também na literatura a mesma tendência verificada 
na análise, aqui, já exposta, isto é a perspectiva de superar a racionalidade técnica na formação do professor. Vários pesquisadores de diferentes países defendem um novo paradigma para a formação de professores, na perspectiva de superar a racionalidade técnica. Estes concebem o professor como um prático reflexivo (Schön,1992; Pèrez Gomez, 1992; Zeichner, 1992; Adler, 1991). Para estes deve ser recuperada a atividade artística e reflexiva do professor, que aprende através da reflexão-na-ação: a partir da análise e interpretação de sua própria atividade.

A reflexão sobre esta história, permite concluir que os programas de formação de professores, não devem ser, simplesmente, dirigidos para suprir carências da formação, nem treinar para a utilização de novas técnicas, mas, precisam, como diz Arroyo(1989) capacitá-los para o domínio da ciência e da técnica e para o equacionamento político da área de especialização, considerando os avanços de cada área e em cada momento histórico. Tais programas devem apontar para uma organização do trabalho, com contornos qualificantes, na perspectiva de possibilitar que o professor se torne um profissional crítico.

A concepção do programa voltado para a formação continuada de professores de química das $1^{\mathbf{a}}$ e $2^{\mathbf{a}}$ Delegacias de Ensino de Ribeirão Preto, sob nossa coordenação, foi pautada na história construída quando da implementação das práticas oficiais deste Estado, voltadas para a formação continuada de professores, desde a década de 70, na busca de superação dos processos anteriormente estabelecidos e no sentido de contribuir para a qualificação dos professores (termo utilizado por Enguita, 1991). Apresentou, ainda, uma perspectiva de superação da exclusiva gestão de órgãos estaduais em tais programas e propôs a criação de um espaço coletivo de produção de saberes curriculares. (termo utilizado por Tardif, 1991)

\section{O programa de formação continuada de professores da região de Ribeirão Preto}

No programa de formação continuada de professores de química, na região de Ribeirão Preto $^{6}$, voltado para a qualificação do professor, este foi concebido como um profissional, que deve ter autonomia, definindo os objetivos e fins de seu trabalho, escolhendo os meios do ensino, como um intelectual transformador (Zeichener, 1993) que procede a reflexões críticas, que analisa o contexto do ensino e da escola, tendo em vista a construção de uma sociedade

6- A coordenação de tal projeto foi minha. Devo ressaltar os trabalhos desenvolvidos pela profa. Dra. Márcia Helena M. Ferraz, no tocante aos aspectos de História da Ciência e as reflexões que estabelecemos em vários momentos do programa. 
mais humana e justa.

Nossa perspectiva era interferir no processo de construção do conhecimento escolar, criando um espaço-tempo para que fossem estabelecidas troca de saberes dos professores provenientes de suas práticas pedagógicas, saberes que brotam da prática e são por ela validados. Fosse estabelecido o confronto do saberes curriculares, ou sejam, experiências discursos, objetivos, métodos e conteúdos, a partir dos quais a escola traduz os saberes sociais. Ao mesmo tempo em que deveriam ser investigadas soluções coletivas para minimizar os impedimentos gerados pelas aviltantes condições de trabalho.

Entendemos que a educação escolar não se limita a fazer uma seleção entre o que há disponível na cultura num dado momento histórico, mas igualmente tem por função tornar os saberes selecionados transmissíveis e assimiláveis, como nos diz Lopes (1997).

O conhecimento escolar seria, então, o resultado de um processo de trabalho social, por meio do qual conhecimento sofre uma série de transformações. O conhecimento científico, produzido no contexto dos centros de pesquisa, é realocado na escola por meio de recontextualizações sucessivas, de acordo com os princípios políticos e culturais dos organismos do estado e de determinadas instâncias da sociedade civil (primordialmente de instituições ligadas à educação: Universidades, Secretaria da Educação, rede editorial, processo estabelecido na escola, etc...) (Santos, 1994).

A lógica que permeia a construção do conhecimento escolar é diferente da que permeia a pesquisa científica. Se o caminho da investigação é para o aprofundamento da análise de um ponto focado, a busca de apoderar-se da matéria em seus pormenores, o caminho da atomização, o professor ao construir conhecimento ao ensinar, ao tornar um objeto de saber produzido pelo cientista em objeto de saber escolar estabelece redes de pensamento na busca da exposição e da globalização.

Conforme Barbieri (1996), na dinâmica da escola há "uma rede de saberes", sendo a forma como a mesma é produzida, a dimensão metodológica. "O professor produz conhecimento ao ensinar. Pois não é possível passar conteúdo e não considerar a transformação que ele sofre tanto com o professor (forma de trabalhá-lo) como com seu aluno (apropriar-se do saber e construir o seu). O processo traz embutido uma produção e um meio que levam a resultados."(Barbieri, 1995)

Se por um lado reconhecemos que a produção do conhecimento escolar é diferente de produção do conhecimento científico, por outro, nos pautamos pela necessidade de aproximar o ensino da realidade social produzida historica- 
mente.

Assumimos, assim, que o conhecimento escolar é apresentado como um texto aberto construído com a participação dos professores e dos alunos, cabendo à escola o papel de tornar públicos os conhecimentos das comunidades científicas relacionando-os com os conhecimentos dos educandos, com o mundo que eles vivem.

Se há um processo para a produção do conhecimento escolar, entendemos que um programa de formação de professores de química ligado a um projeto que busca a autonomia do professor, deve interferir nas condições de trabalho do mesmo por meio da criação de um espaço coletivo de produção de conhecimento escolar.

Neste sentido, organizamos um programa que constava de: Orientações Técnicas na Oficina Pedagógica da $2^{\mathrm{a}}$ Delegacia de Ensino de Ribeirão Preto, constituição de um grupo de trabalho e de um arquivo temático, situados na Universidade.

As Orientações Técnicas (OTs) foram concebidas como um espaço e tempo onde professores da rede e da Universidade pudessem conjuntamente construir conhecimento. Estas foram assim compreendidas como um programa de caráter formal acentuado pela dialética da separação e da articulação. Ou seja, como um tempo separado das práticas - consagrado à aquisição intensiva de capacidades e competências - pois os conhecimentos teóricos e práticos aumentam e não podemos adquiri-los exclusivamente no círculo dos acontecimentos do vivido (Malglaive, 1995). As OTs, simultaneamente deveriam articular essas práticas que se separam, pois a elas devem conduzir o processo de formação.

Nestes eventos procedemos ao estudo sobre temas da Proposta Curricular Oficial, introduzindo elementos que permitissem novos patamares de reflexão sobre os mesmos, na busca de soluções coletivas para a implementação da proposta oficial para o ensino de Química.

A dinâmica estabelecida pressupunha que o tema selecionado no encontro dos professores (OTs), fosse aprofundado pelo grupo de voluntários em conjunto com os especialistas, testado nas escolas e objeto de organização do arquivo.

O que se objetivava nos encontros era construir coletivamente projetos de transposição didática (termo usado por Astolfi, J e Develay, M., 1990 ) para o assunto, da Proposta Curricular oficial, escolhido pelos professores. Era apresentado, assim, num primeiro momento, o conhecimento produzido na escola, através de relatos da prática pedagógica e confrontado com os expostos 
pelos especialistas da Universidade; eram introduzidas atividades que serviam para desencadear as discussões, tais como atividades práticas, vídeos, textos ou exposição de um problema. Em seguida, os professores avaliavam atividades propostas e promoviam novas sínteses.

Era pressuposto que o ensino de química deveria "visar à aprendizagem dos conceitos, princípios, teorias e leis desta ciência; à compreensão da natureza e processo de produção desse conhecimento, bem como à análise da sua aplicação na sociedade, numa trajetória que envolva transmissão/assimilação ativa/reavaliação crítica do conhecimento" 7

Neste sentido, o eixo dos trabalhos voltados para a construção da metodologia de ensino de química, que pressupunha uma reorganização, reestruturação do conhecimento visando esse ensino, foi apoiado em três princípios orientadores:

- a experimentação como um dos momentos de reelaboração do conhecimento;

- o tratamento do conhecimento científico sob um perspectiva histórica;

- a análise crítica da aplicação do conhecimento na sociedade.

Nosso objetivo era desencadear, através das Orientações Técnicas, um processo de transformação e reconstrução de conhecimento, produzir um momento de estranhamento, criando uma certa distância crítica, voltada para a produção do conhecimento escolar. Estas tornaram-se a ponta de lança das outras ações que paulatinamente foram sendo construídas: a formação de um grupo de estudos de professores e a organização de arquivo de material didático.

Paralelamente foi desencadeado um processo para interferir nas condições de trabalho, buscando soluções coletivas de problemas cotidianos dos professores (grupo de estudos e arquivo temático).

O grupo de ensino de química, foi formado tendo em vista a criação de um espaço de estudoe reflexão. Previa-se que os professores voluntários, mediante encontros semanais, sob a orientação da coordenadora do projeto, pudessem aprofundar as reflexões sobre a prática pedagógica a partir da troca de experiência entre os pares, da introdução de informações obtidas por meio de incursões no acervo de material didático, pára-didático e bibliografia específica do acervo das pesquisadoras do projeto, localizado na Universidade.

$\mathrm{O}$ arquivo temático foi concebido como um conjunto de materiais didáti-

7- São Paulo. (Estado). Secretaria da Educação. Coordenadoria de Estudos e Normas Pedagógicas. Proposta Curricular para o Ensinode Química-2ºrau. São Paulo, SE/CENP, 1986. 
cos, voltados para os três eixos da Proposta Curricular, composto por materiais selecionados pelos professores participantes do grupo de ensino, alunos do curso de Licenciatura e pelas especialistas em ensino de química e história da ciência, do projeto.

Durante o ano de 1996, foram realizadas seis Orientações Técnicas sobre os seguintes temas: Uso dos materiais, Metalurgia e siderurgia no Brasil, A química orgânica no ensino médio de química, Estudo dos Alimentos, Petróleo, Fermentação.

A maioria dos professores das duas Delegacias de Ensino de Ribeirão Preto participaram das Orientações Técnicas. $\mathrm{O}$ quadro abaixo expressa a distribuição dos participantes.

\section{Quadro I}

\section{Orientações Técnicas a professores de química das $1^{a}$ e $2^{a}$ Delegacias de Ensino de Ribeirão Preto.}

\begin{tabular}{|c|c|c|c|}
\hline Datas & \multicolumn{2}{|c|}{$\mathrm{n}^{2}$ de participantes } & total \\
\hline & $1^{2} \mathrm{DE}$ & $2^{2} \mathrm{DE}$ & 17 \\
\hline $08 / 05$ & 6 & 11 & 22 \\
\hline $13 / 06$ & 12 & 10 & 26 \\
\hline $9 / 08$ & 14 & 12 & 25 \\
\hline $10 / 09$ & 12 & 13 & 29 \\
\hline $9 / 10$ & 13 & 16 & 22 \\
\hline $27 / 11$ & 10 & 12 & \\
\hline
\end{tabular}

Das treze escolas estaduais que ministram o ensino médio de química da cidade de Ribeirão Preto, dez tiveram seus professores, pelo menos uma vez, freqüentando as Orientações Técnicas. Estiveram presentes professores das seguintes cidades: Ribeirão Preto, Dumont, Cravinhos, Serrana, Guatapará.

Do total de participantes das Orientações Técnicas, nove professores compareceram a todos os encontros e nove faltaram a apenas um.

Dentre os professores que freqüentaram as Orientações Técnicas, cinco participaram continuamente das atividades do grupo de estudos que foi criado a partir de agosto de 1996.

O grupo iniciou suas reflexões sobre os tópicos levantados nas Orientações Técnicas, mas aos poucos foram surgindo problemas provenientes da prática pedagógica de cada participante o que foi implementando nova dinâmica ao mesmo. Foram discutidas experiências vividas pelos participantes em 
relação ao ensino dos temas selecionados, divulgadas soluções encontradas pelos participantes para vencer as aviltantes condições de trabalho e trocados materiais didáticos utilizados pelos professores em suas aulas.

O grupo foi responsável pela construção do arquivo temático que possibilitou ao mesmo, por meio de um trabalho contínuo, a reflexão sobre aspectos anteriormente não enfatizados em sala de aula e nem mesmo nas Orientações Técnicas, mensais.

$\mathrm{O}$ arquivo, construído, contribuiu para estudos dos alunos do curso de formação de professores, que puderam, analisar escolha de textos e material de apoio, pelos professores, o que lhes forneceu pistas para refletirem sobre os conhecimentos curriculares dos professores que já exercem a profissão.

Este grupo encerrou seus trabalhos semanais, quando foi iniciado o Programa Pró-Ciência ${ }^{8}$, por nós coordenado, tendo seus integrantes participado do novo espaço de estudo e contribuído divulgando os resultados do trabalho anterior, principalmente o arquivo temático.

\section{os alimentos \\ Uma incursão sobre um dos temas do programa: o estudo sobre}

Com o intuito de exemplificar nossa metodologia de trabalho focalizarei o desenvolvimento do estudo sobre os alimentos, tema, escolhido pelos professores, que foi objeto de uma Orientação Técnica, investigado em várias sessões de estudo do grupo de professores e objeto da organização do arquivo temático. Este, é um dos tópicos da Unidade seis da Proposta Curricular para o Ensino de química- $2^{\circ}$ grau, ora vigente, voltada para o estudo da química orgânica, devendo ser tratado a partir três princípios orientadores: a história da ciência, o cotidiano e a experimentação.

A química orgânica vêm sendo tratada no ensino médio por poucos professores e os que a tem introduzido em suas aulas, sem estabelecerem correlações com a vida dos alunos, têm apresentado conceitos prontos, priorizando o ensino da nomenclatura e das classificações das funções, em detrimento do estudo dos fenômenos.

A Proposta Curricular, por outro lado, sugere que a química orgânica seja tratada através de estudos temáticos das diferentes funções orgânicas,a partir do estudo das propriedades, passando pelas classificações e nomenclatu-

8- Programa Pró-ciência. Projeto "O trabalho do professor de química e a produção do currículo: formação continuada de professores de química". Coor. Antonio Cláudio Tedesco e Natalina Ap. Laguna Sicca. FAPESP. 
ra oficial. Sugere ainda que se estabeleça ligações com a vida dos alunos na perspectiva de que os mesmos possam estabelecer juízos de valor sobre a aplicação deste conhecimento no mundo em que vivem.

Pudemos constatar, que a minoria dos professores participantes da Orientação Técnica ministram esta parte do programa, sob diversos argumentos. Entretanto alguns dos presentes relataram práticas interessantes, quanto ao estudo sobre os alimentos, que apontam para a direção indicada na Proposta Curricular.

Uma das professoras, por exemplo, realizou com suas alunas uma investigação sobre os alimentos consumidos durante uma semana, pelos alunos de uma determinada classe e em seguida estudou com os mesmos os tipos de funções orgânicas dos aditivos mais utilizados (professora do CEI José Martiminiano da Silva) ${ }^{9}$.Outra professora, discute artigos de jornais, que a mesma coleciona, com tabelas sobre os símbolos utilizados para os aditivos. Esta solicita que os alunos leiam os artigos, interpretem tabelas e quadros, leiam a legislação vigente. Em seguida aprofunda o estudo dos aspectos mais voltados para a química orgânica (professora da EESG Cônego Barros). Uma terceira destaca neste estudo, os aspectos voltados para a fermentação e a obtenção de alimentos: pão, coalhada, bebidas alcoólicas. Procede a visitas a indústrias alcool-açucareiras da região, realiza demonstrações estabelecendo relações com a vida dos alunos. (professora da EEPSG Nestor G de Araújo).

Nosso objetivo foi defender que, na perspectiva de implementar a Proposta Curricular, devemos abordar o tema nos seus aspectos bioquímicos e culturais, estabelecendo uma ponte entre a ciência e a cultura.

Nesse sentido, procedemos a incursões sobre os aspectos históricos da introdução de alimentos no Brasil e analisamos historicamente a produção e comercialização dos mesmos, destacando a introdução no Brasil do milho, banana e mandioca.

Procedemos por exemplo, a uma exposição sobre a introdução da banana no Brasil. Esta teria sido originária do Sudeste Asiático. "Alexandre Magno refere-se no vale do Indo em 327 a. C e os árabes devem ter desempenhado um papel importante na difusão desta planta, que assim, teria chegado à Àfrica oriental e ao Mediterrâneo"(Ferrão, 1992). Discutimos sobre as controvérsias de sua introdução na América, mas, como tudo parece indicar, os portugueses conheceram as bananas no Mediterrâneo ou na costa ocidental africana, até onde estendia neste tempo a influência árabe, e a introduziram nas ilhas de

9- Segundo a mesma, teria sofrido influência do trabalho do prof. Mansur Lutfi sobre o assunto. 
Cabo Verde e em São Tomé, de onde a bananeira deste tipo foi trazida para o Brasil.(Ferrão, 1992) Chegamos a discutir a situação atual das exportações de bananas e a importância das mesmas na alimentação do brasileiro.

Após esta exposição os professores procederam a uma atividade para identificação de amido e açúcares em bananas verdes e maduras.

Refletimos conjuntamente sonbre a alimentação, atual, do brasileiro enfocando problemas na comercialização e armazenamento de alimentos.

Aprofundamos os aspectos bioquímicos através do estudo dos lipídeos (Snyder, 1991) (Sicca, 1996), proteínas(Sicca, 1996), amido(Cruz, 1995), açúcar e vitamina C (Silva,1995), partindo da realização pelos grupos de professores de atividades experimentais, pautados nos roteiros distribuídos. Enfatizamos, ainda, durante os trabalhos, a importância de serem tratados os aspectos energéticos do consumo dos alimentos, geralmente esquecidos na sala de aula, sugerindo portanto o estudo da combustão dos alimentos.(São Paulo/SE,1979)

A metodologia previa a identificação de diferentes tipos de alimentos, mediante práticas simples e possíveis de serem realizadas em laboratórios das escolas. Essas, foram selecionadas pelos professores do grupo de ensino, sendo que uma delas foi sugerida por um pesquisador do Departamento de Biologia. As selecionadas mostraram uma estreita ligação com a vida dos alunos, como podemos perceber: determinação de amido em bananas verdes e maduras; determinação de vitamina $\mathrm{C}$ em suco de laranja, comprimidos de vitamina C; determinação de saturações em óleos de amendoim, girassol, oliva tendo em vista a discussão do colesterol; determinação de proteínas no ovo, feijão, arroz; identificação de açúcares.

Os professores em grupo deveriam testar e avaliar uma atividade, sendo que no final, todos os grupos relatariam suas análises sobre as mesmas, tendo em vista a viabilidade de aplicação na escola, aos conceitos envolvidos, a legibilidade do roteiro, aorganização da mesma.

Esta dinâmica foi implementada no sentido de propiciar o contato do professor com um maior número de atividades práticas e contribuir para que $o$ mesmo estabeleça processos de divulgação de suas análises e perceba a importância da discussão entre os pares. ${ }^{10}$

A dinâmica estabelecida possibilitou intenso debate sobre os resultados das atividades práticas, com troca de saberes entre os professores. Por exemplo, a atividade voltada para a determinação da vitamina C, extraída de uma revista da Sociedade Brasileira de Química voltada para o ensino médio, des-

10- 'Procedimento utilizado em trabalhos do Laboratóriode Ensino de Ciências da FFCLRP 
conhecida até então pela maioria dos professores presentes, foi enriquecida por sugestões dos professores para que, a partir da mesma, fossem estabelecidos projetos investigativos a serem realizados pelos alunos, tais como: a determinação da vitamina $C$ de sucos de laranja comprados de diferentes marcas, a determinação do teor de vitamina $\mathrm{C}$ em laranjas colhidas em intervalos de tempo diferentes, a determinação de vitamina $\mathrm{C}$ em sucos comprados e guardados durante intervalos de tempo diferentes.

Os professores discutiram diferentes aspectos relativos aos roteiros das aulas práticas. Criticaram sua falta de clareza. Notaram que roteiros originados dos livros didáticos contêm muita imprecisão, o que não ocorreu com materiais oficiais e oriundos de revistas de divulgação científica.

Houve concordância, entre os professores, quanto à necessidade de atividades práticas e inclusão do cotidiano nas aulas. E discordância quanto a introduzir tópicos relativos à História da Ciência baseados em dois argumentos: tal disciplina inexistiu quando estudaram química e há escasso tempo nas aulas para novos temas.

No final dos trabalhos foi distribuída a relação dos materiais já selecionados e pertencentes ao arquivo de material didático sobre o estudo dos alimentos organizado pelo grupo de professores que vinham se reunindo semanalmente. $\mathrm{Na}$ época, constava de: 5 tabelas e quadros; 15 artigos de revistas e jornais; 11 capítulos de livros; 2 livros; 12 roteiros de aulas práticas; 3 pastas de Prática de Ensino de Química; 1 vídeo; 5 artigos de história da ciência.

$\mathrm{O}$ arquivo temático é uma construção coletiva do gnupo de professores voluntários e dos alunos da Prática de Ensino de Química (disciplina da Licenciatura) que está a disposição de todos professores da rede estadual de ensino. Este é composto por:

a) materiais selecionados pelo grupo de professores: textos de professores da rede contendo registros de aulas ministradas, artigos de revistas de divulgação, vídeos, roteiros de experimentos;

b) materiais selecionados e formulados por alunos do curso universitário de formação de professores, das disciplinas Programação de Cursos e Prática de Ensino de Química;

c) material do acervo pessoal das pesquisadoras responsáveis pelo programa: coleção de livros didáticos antigos desde o início do século; projetos atuais de ensino de química, nacionais e internacionais; coletânea de atividades práticas e artigos sobre o cotidiano; livros didáticos e para-didáticos atuais; Pastas de Prática de Ensino de Química (1980-1996); artigos e livros sobre temas voltados para a formação de professores, ensino de química história da 
ciência; programas oficiais de ensino de química e instruções metodológicas, desde o início do século; revistas atuais e antigas voltadas para o ensino médio de química.

Esta Orientação Técnica, representou o ponto de mutação do programa, pois os professores do grupo de química começaram a coordenar atividades, a apresentar notícias ou publicações pertinentes ao tema e divulgar entre os companheiros (processos estimulados pela coordenação). Contudo, deve ser registrada certa resistência de alguns professores quando integrantes do grupo de química coordenaram as discussões."

\section{Considerações Finais}

Este programa nos possibilitou confirmar algumas suposições iniciais. Embora as Orientações Técnicas tenham sido espontaneamente frequentadas pelos professores, que cada vez mais participaram ativamente das mesmas, embora tenham sido avaliadas positivamente pelo responsável da Oficina Pedagógica, no ano seguinte por problemas administrativos, uma das Delegacias de Ensino optou pelo corte de Orientações Técnicas de todas as disciplinas e a outra só as retomou no segundo semestre alegando falta de verbas. Fica evidente mais uma vez a descontinuidade de programas estritamente ligados a burocracia oficial, provocados por medidas administrativas sem uma avaliação sobre os aspectos pedagógicos dos mesmos, nos deixando cada vez mais certos da necessidade da gestão de programas de formação continuada de professores ser fora do âmbito da SE. Porém, também encontramos muitas dificuldades para manter projetos sem um apoio financeiro para professor, que para participar de grupos de estudos, necessariamente acrescenta horas de trabalho, sem remuneração, ficando sobrecarregado financeiramente e em sua jornada de trabalho. Mesmo assim, devemos registrar a vontade manifesta pelos professores e mesmo a ansiedade de partilhar e confrontar saberes na busca de soluções de problemas comuns, de conhecer novos materiais e bibliografias, ainda que para isto tivessem que aumentar sua carga de trabalho e utilizar recursos próprios, pelo menos para locomoção.

Pudemos concluir também, que dos três princípios orientadores para a construção da metodologia para o ensino de Química, sugeridos na Proposta Curricular, o que tem sido mais utilizado pelos professores no processo de elaboração do conhecimento escolar é o referente a introdução do cotidiano no ensino de química, visando estabelecer elos com a vida dos alunos, seja no

11- coordenação do programa: profa. Dra. Natalina A. L. Sicca.;orientação em assuntos de História da Ciência: profa. Dra. Márcia H. M. Ferraz; grupo de ensino de química: Regina H. Roque, Denise M. Gonçalves, Rosalice C. dos Santos, Joanice Dellamole, Soraia Merino 
início do estudo de um determinado tópico ao partir do conhecimento do aluno, seja para proceder a uma análise sobre a aplicação do conhecimento científico. Os professores salientaram, durante todo o programa, a falta de condições de trabalho para utilizar atividades práticas em suas aulas e a dificuldade de introduzir aspectos históricos devido a deficiência na formação universitária.

\section{Referências Bibliográficas}

ADLER, S. The reflective practitioner and the curriculum of teacher education. Journal of education for teaching, 17, (2): 139-151, 1991

APPLE, Michael W. Educação e poder. Tradução por Maria Cristina Monteiro. Porto Alegre: Artes Médicas, 1989. 201p.

ARROYO, Miguel G. A formação, direito dos profissionais da educação escolar. In: ARROYO, Miguel G. Política de capacitação dos profissionais da educação. Belo Horizonte: FAE/IRHJP, 1989. p.35-71.

ASTOLFI, Jean Pierre e Michel Develay.(1990) A didática das Ciências. tradução por Magda Sento Sé Fonseca. Campinas, SP: Papirus.

BARBIERI, M.R. A Construção do conhecimento científico: o processo educacional da construção do saber científico.(mimeo.) 1996.

BARBIERI, M.R. Ensino de Ciências: formação de professor. Ribeirão Preto, 1995 (mimeo.)

Cruz, R. Bananas: quanto mais maduras, mais doces. (1995) in: Roque Cruz. Experimentos de química em micro escala orgânica. Ed. Scipione, ,p.32.

ENGUITA, Mariano Fermández. A ambigüidade da docência: entre o profissionalismo e a proletarização. Teoria \& Educação. Dossiê: interpretando o trabalho docente. Porto Alegre, n. 4, p. 41-61, 1991.

Ferrão, J. E. M. (1992). A aventura das plantas e os descobrimentos portugueses. Instituto de Investigação Científica Tropical, Rio Tinto, Portugal,

Jesten,M. et alii. Chemistry of living systems.(1991) In Jesten,M. et alii: World of Chemistry. Saunders College Publishing, Philadelphia, p.446-488.

LOPES, A.R.C. Currículo e a construção do conhecimento na escola: controvérsias entre conhecimento comum e conhecimento científico no ensino de ciências físicas. Moreira, A.F.(org.). Conhecimento Educacional e formação do professor. Papirus, 1994.p.39-52.

LOPES, A.R.C. Conhecimento escolar em química-processo de media- 
ção didática da ciência. Química Nova. 5(20):563-569. 1997.

MALGLAIVE, Gerard. 1995. Ensinar Adultos: trabalho e pedagogia. tradução por Maria Luiza Alvarez Pereira e outros. Porto:Porto Editora.

MOREIRA, Antonio F et al. (1994) Conhecimento educacional e formação de professor: questões atuais.Campinas:Papirus. 138p

PÉREZ GÓMEZ, Angel. O pensamento prático do professor: a formàção do professor como profissional reflexivo. In: NÓVOA, António (Coord.). Os professores e a sua formação. Lisboa: Publicações Dom Quixote, 1992. p.93-114.

SANTOS, L.L.C.P O processo de produção do conhecimento escolar e a didática. In: Moreira, A.F.(org.). Conhecimento Educacional e formação do professor. Papirus, 1994. P.27-52.

SÃO PAULO (Estado). Secretaria da Educação. Coordenadoria de Estudos e Normas Pedagógicas. Proposta Curricular para o ensino de química - $2^{\circ}$ grau. São Paulo: SE/CENP, 1986. 40p. (Versão preliminar).

SÃO PAULO (Estado). Secretaria da Educação. Coordenadoria de Estudos e Normas Pedagógicas. Proposta Curricular para o ensino de química - $2^{\circ}$ grau. São Paulo: SE/CENP, 1988. 38p.

SÃO PAULO (Estado). Secretaria da Educação. Coordenadoria de Estudos e Normas Pedagógicas. Subsídios para a Implementação da Proposta Curricular de Química para o $2^{\circ}$ grau. São Paulo: SE/CENP/ FUNBEC, 1978, 1978, 1979. 3v

São Paulo(Estado). Secretariada Educação. Coordenadoria de Estudo e Normaas Pedagógicas.. Subsídios para a Implementação da Proposta Curricular de Química para o $2^{\circ} \mathrm{grau}$. Alimentos como fonte de energia v.II, São Paulo, SE/FUNBEC/CENP, 1979, p.62-64.

SCHÖN, Donald A. Formar professores como profissionais reflexivos. In: NÓVOA, António (Coord.). Os professores e a sua formação. Lisboa: Publicações Dom Quixote, 1992. p.77-91.

SICCA, N, A.L Qual a diferença entre óleos e graxas? Como diferenciar óleos com diferentes números de insaturações.(mimeo.)

SICCA, N. A. L. Identificação de proteínas utilizando o método de Lowry (mimeo.)

SICCA,Natalina A.L. A memória da formação de professores de Química: buscando meu enredo. Campinas:1996. 280p. Tese de Doutorado em Educação, Universidade Estadual de Campinas

SILVA, L S; Ferreira, G. A.; Silva, R. R. A procura da vitamina C. 
Química Nova na escola.(2),nov., 1995.p.31-32

SILVA, M. B. N. Vida privada e quotidiano no Brasil - na época de D. Maria I e de D. João VI. Lisboa, referência/editorial estampa, 1993. p.217225.

SNYDER, C. H. Food. Fuel for human engine. In: The extraordinary Chemistry of ordinary things. New York. John Wiley \& Sons, Inc. 1992, p.329-348.

TARDIF, Maurice. et al. Os professores face ao saber: esboço de uma problemática do saber docente. Teoria \& Educação, Dossiê: interpretando o trabalho docente. Porto Alegre, n. 4, p. 215-234, 1991.

ZEICHNER, Ken. Novos caminhos para o practicum: uma perspectiva para os anos 90. In: NÓVOA, António. (Coord.). Os professores e a sua formação. Lisboa: Publicações Dom Quixote, 1992. p.115-138.

ZEICHNER, Kenneth M. El maestro como profesional reflexivo. Cuadernos de Pedagogía, Monográfico El Professorado. Valencia, n. 220, p. 44-49, dec. 1993.

\section{ABSTRACT}

This article focuses the development of the project on continuing education of inservice chemistry teachers. This project was developed in Ribeirão Preto, SP, Brazil. It aims the construction of space-time for collective reflection about construction of school knowledge in chemistry. When I analyse the conditions of work (of these teachers) I see several trammels to production of a methodology of teaching, so I prepared a program to help teachers to take over this challenge. This paper describes the methodology about one topic of this project (the study of food).

Key Words: education; chemistry; chemistry teaching; inservice chemistry teacher's education.

Palavras Chave: educação; química; ensino de química; formação em serviço de professores de química. 


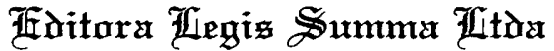 \\ Rua D. Alberto Gonçalves, 1355}

Fone/fax (016) 6260492 - Ribeirão Preto SP. 
